\title{
CARACTERIZAÇÃO DO CONFLITO DE USO E OCUPAÇÃO DO SOLO NAS ÁREAS DE PRESERVAÇÃO PERMANENTE DO RIO APEÚ, NORDESTE DO PARÁ
}

\author{
Shislene Rodrigues de Souza ${ }^{1}$, Maria de Nazaré Martins Maciel $^{2}$, Francisco de Assis Oliveira ${ }^{3}$, \\ Stephan de Almeida Jesuíno ${ }^{4}$ \\ ${ }^{1}$ Eng ${ }^{\text {a }}$ Florestal, M.Sc., UFRA, Manaus, AM, Brasil - xflorest@ gmail.com \\ ${ }^{2}$ Eng $^{\text {a }}$ Florestal, Dr ${ }^{\mathrm{a}}$., Depto. de Ciências Florestais, UFRA, Manaus, AM, Brasil - nazare.maciel@ufra.edu.br \\ ${ }^{3}$ Eng. Florestal, Dr., Instituto de Ciências Agrárias, UFRA, Manaus, AM, Brasil - francisco.oliveira@ ufra.edu.br \\ ${ }^{4}$ Eng. Florestal, M.Sc., UFRA, Manaus, AM, Brasil - stephan.almeida@gmail.com \\ Recebido para publicação: 22/10/2010 - Aceito para publicação: 24/08/2012
}

\begin{abstract}
Resumo
Dentro do contexto regional, entende-se que a ocorrência de problemas ambientais causados na região é procedente de uma formação histórica de colonização na Amazônia que desvalorizava os maciços florestais. Nesse sentido, visou-se realizar o mapeamento e a identificação do conflito de uso e ocupação nas áreas de preservação permanente dessa bacia de acordo com o Código Florestal (Lei $\mathrm{n}^{\circ}$ 4.771/65) e a Resolução CONAMA n ${ }^{\circ} 303$, de 2002. A partir de mapas de cobertura vegetal e uso do solo e aplicando-se técnicas de geoprocessamento, chegou-se ao resultado de que as classes solo exposto e pastagem foram as unidades de uso que mais se evidenciaram no local. Dentro do contexto histórico da região, pode-se dizer que as atividades agropecuárias construídas ao longo do tempo não deixaram escapar as áreas de preservação permanente, ainda que o uso indevido de $22 \%$ das matas ciliares seja considerado baixo.

Palavras-chave: Bacia hidrográfica; geoprocessamento; mata ciliar.
\end{abstract}

\begin{abstract}
Conflict characterization over the use and occupation of soil in permanent conservation areas of river Apeú, northeastern Pará. Within the regional context, it is understood that environmental problems occurrence in the region are result of the historical formation of colonization which devalued the massive Amazon forest. Therefore, mapping and identification of the conflict in Permanent Preservation Areas (PPAs) of this basin were performed, according to the Forest Code (Law no. 4.771/65) and the 2002 CONAMA determination registered under the number 303. It was used maps in which the natural cover and soil use were depicted by using GIS techniques, as result exposed soil and pasture revealed as the most apparent ones. Within the historical context of the region, it can be said that long agricultural activities reached the permanent preservation areas, in spite of the level of $22 \%$ of riparian areas misusing is considered low.

Keywords: River basin; geoprocessing; riparian areas.
\end{abstract}

\section{INTRODUÇÃO}

A Amazônia é uma região que chama atenção pela importância da preservação do meio ambiente. A representatividade destacada do valor ambiental resguarda contradições que refletem bem a sua formação. Entre elas estão a condição de ter uma das maiores áreas de biodiversidade do mundo e, ao mesmo tempo, apresentar os mais graves índices de destruição dos recursos naturais. Os interesses econômicos que movimentam o mercado local e ao mesmo tempo a intervenção humana nos recursos naturais são as principais causas desse problema.

$\mathrm{Na}$ Amazônia, o uso indevido dos seus produtos naturais trouxe, entre outras consequências, níveis elevados de desmatamento nas áreas florestais. Com relação ao assunto, Lentini et al. (2005) dizem que, originalmente, a Amazônia Legal continha 73\% de cobertura florestal. Em 2004, cerca de 14\% da 
Amazônia já haviam sido desmatados. Ao considerar apenas o bioma Amazônia, o desmatamento atingiu pelo menos $17 \%$ em 2004.

Dentro do contexto regional, entende-se que a forte exploração dos maciços florestais aconteceu durante a formação histórica de colonização (RIBEIRO et al., 2005), quando diversas atividades foram implementadas sem levar em consideração os aspectos socioambientais de cada local. Entre essas atividades estão a conversão de terras à exploração agrícola e pecuária, que aparecem como as principais áreas atrativas de investimento na região, logo depois do setor madeireiro (LENTINNI et al., 2005).

Santos e Câmara (2002) fazem referência a diversos níveis de degradação que ocorreram nos biomas brasileiros associados a atividades econômicas desenvolvidas ao longo do tempo. No que tange particularmente às atividades ligadas ao meio rural, segundo Pissati e Archela (2009), os problemas gerados decorrem da complexidade e heterogeneidade ambiental presentes nesse espaço. Já nas áreas urbanas, a condição de aglomeração de pessoas em constante desenvolvimento civilizacional reproduz processos ainda mais graves, pois causam problemas invariáveis, que muitas vezes são desconhecidos em nível científico.

Ambrósio et al. (2008) destacam a influência do uso antrópico nas mudanças sucessivas, identificando um fenômeno caracterizado pela dinâmica da relação de causa e efeito entre seis fatores: demográfico, econômico, tecnológico, político e institucional, sociocultural e ambiental. Numa condição de resposta do meio natural a essa complexa rede, a fragmentação florestal surge como uma consequência, dada por um processo de rompimento da continuidade das unidades de paisagem que, em determinadas situações, leva ao desflorestamento total de alguns biomas.

Por outro lado, a gravidade do desflorestamento pode ser associada ao tipo de cobertura substituída e ao procedimento adotado para sua formação (TUCCI, 2002). No caso da Amazônia, muitos desses processos ocorreram por ocupações desordenadas acompanhadas de atividades produtivas que desvalorizaram os maciços florestais, principalmente nas chamadas matas ciliares (MARTINS, 2001; SOARES, 2008).

As matas ciliares são vegetações que ocupam as margens de cursos d'água e são de extrema importância para a estabilidade dos mesmos, já que são atribuídas a elas algumas funcionalidades, como: infiltração de água no solo, qualidade da água a partir da proteção de eventos externos, sombreamento, estabilidade térmica da água, minimização de processos erosivos e abrigo e alimento para grande parte da fauna aquática (LIMA; ZAKIA, 2004).

A função ecológica das populações vegetativas tendeu a nortear novos valores preservacionistas aos remanescentes florestais que, em condições adversas, são testados na sua capacidade de resiliência no meio em que se encontram. No caso das matas ciliares, muitas sofreram impactos relevantes em ambientes inóspitos criados por atividades incompatíveis com a sua sobrevivência. Alguns autores já haviam manifestado a preocupação quanto ao uso indevido oriundo de atividades econômicas, como a pecuária, nesse tipo de vegetação. Entre eles estão Soares (2008) e Ribeiro et al. (2005).

Nesse âmbito de manutenção das florestas à margem de cursos d'água, a Lei Federal 4.771/65 (BRASIL, 1965) e a Resolução $n^{\circ}$ 303/02 do CONAMA (BRASIL, 2002) são as leis que contemplam juridicamente o sistema nacional brasileiro (alteradas por medidas provisórias) quanto a essas questões ambientais. Ao atribuir a importância da evolução jurídica que as áreas de preservação permanente ganharam ao longo do tempo, pode-se dizer que, enquanto o Código Florestal brasileiro (Lei 4.771/65) citou pela primeira vez a obrigação de proteção dessas áreas pelos proprietários, a resolução do Conama permitiu esclarecer pontos deixados pelo Código, antes não abordados na legislação (BORGES et al., 2009).

A regularização nos processos que intervêm nos recursos naturais trouxe às bacias hidrográficas a responsabilidade de medir os impactos deixados no ambiente, pois, segundo Rodrigues e Carvalho (2005), a bacia hidrográfica é um meio natural espacialmente definido, no qual seus elementos mantêm relações dinâmicas entre os componentes físicos, biológicos e socioeconômicos. Adicionalmente, Balbinot et al. (2008) comentam que, para avaliar o efeito que teria qualquer perturbação numa bacia hidrográfica, é necessário antes conhecer bem as características hidrológicas do ecossistema natural. Entre essas características estão as vegetações que recobrem a rede de drenagem de um rio. Sobre esse parâmetro, a utilização de imagens está se tornando cada vez mais comum, devido à potencialidade dada no acompanhamento e na avaliação da dinâmica de ocupação desses elementos.

Numa visão de ordenamento espacial das atividades de exploração e conservação de áreas, Lorena (2001) ressalta que o grande número de dados disponíveis em função do número de plataformas 
orbitais em operação tem colaborado para os estudos das variações dos alvos que ocorrem na Terra. Nesse sentido, o processo de análise de mudanças a partir de técnicas de sensoriamento remoto e geoprocessamento são convenientes para bacias hidrográficas de grande influência.

A bacia hidrográfica do rio Apeú (BHRA), como uma rede de drenagem expressiva na região do nordeste do Pará, apresenta instabilidades caracterizadas pela falta de planejamento ambiental na regularização do uso e ocupação das suas áreas de preservação permanente (APPs). Este estudo teve como objetivos mapear e identificar o conflito de uso e ocupação nas áreas de preservação permanente dessa bacia, bem como quantificar a área da bacia que estava inadequada à legislação (Lei no 4.771/65 e a Resolução do CONAMA nº 303, de 2002).

\section{MATERIAIS E MÉTODOS}

\section{Área de estudo}

A BHRA ocupa uma área de aproximadamente $315 \mathrm{~km}^{2}$ (SANTOS, 2006; JESUS, 2009) e está localizada no nordeste do Pará, ou, mais precisamente, na mesorregião metropolitana de Belém. A bacia se estende entre as coordenadas $1^{\circ} 13^{\prime} 10^{\prime \prime}$ e $1^{\circ} 27^{\prime} 37^{\prime \prime}$ de latitude Sul e $48^{\circ} 04^{\prime} 42^{\prime \prime}$ e $47^{\circ} 53^{\prime} 30^{\prime \prime}$ de longitude Oeste, sendo que aproximadamente $77 \%$ de sua área pertence ao município de Castanhal, $16 \%$ ao município de Santa Izabel do Pará e 7\% ao município de Inhangapi. O plano diretor de Castanhal reconhece a região, que leva o nome do rio, como uma Macrozona de Gestão Ambiental, levando em conta, entre outros parâmetros, que a bacia hidrográfica é unidade física territorial de planejamento e gestão ambiental (CASTANHAL, 2006).

O rio Apeú nasce na fazenda Buriti, no município de Castanhal, e desemboca no rio Inhangapi (SANTOS, 2006). O rio Apeú tem ainda, como afluentes, os igarapés Macapazinho, Castanhal e Americano (FERREIRA, 2003), além do Janjão, Fonte Boa, Marapanim, Taiteua, Papuquara, Capiranga, Itaqui e São João (ARAÚJO, 1997).

Geologicamente, essa área é constituída dos terrenos terciários da Formação Barreiras, além dos sedimentos recentes do Quaternário, representados por cascalhos, areias e argilas inconsolidadas, que ocorrem nas faixas estreitas e descontínuas, acompanhando os cursos d'água (BRASIL, 1974). As feições geomorfológicas caracterizam-se pela presença de colinas de topos aplainados e moderadamente dissecados, compondo um dos setores do Planalto Rebaixado Amazônico, e a planície sedimentar do Pleistoceno e do Holoceno.

A cobertura vegetal está sob domínio da Floresta Ombrófila Densa (VELOSO; GOES FILHO, 1982) ou Floresta Densa de Terra-Firme, que pode ser vista margeando os rios, onde passa a se caracterizar como Floresta de Igapó ou Floresta de Igapó Estacional (SILVA, 1995). Em menor proporção, são também encontradas formações vegetativas conhecidas popularmente como capoeiras, originadas a partir da intervenção humana ao longo da ocupação na região.

\section{Sistematização e georreferenciamento dos dados utilizados}

O processo de análise do uso nas áreas de preservação permanente (APPs) iniciou com a reunião das informações da área de estudo, apoiada, de um lado, em bases digitais da imagem Landsat georreferenciada de órbita/ponto 223/061 (bandas TM 3, 4 e 5) e, de outro, em base cartográfica compilada a partir de dados digitais disponibilizados pelo Instituto Brasileiro de Geografia e Estatística (IBGE) e Diretoria de Serviço Geográfico (DSG), na escala de 1:100.000, que contiveram, entre outros elementos, a rede de drenagem da área de abrangência do local.

O estudo, de cunho multitemporal (anos de 2001, 2004 e 2008), contou ainda com o tratamento e análise do banco de dados realizadas nos programas Envi 4.5 (Environment for Visualizing Images (ENVI) 2009) e ArcGis 9.3 (Environmental Systems Research Institute (ESRI) 2009), que fundamentaram as outras etapas.

\section{Delimitação da área da bacia e não das APPs}

Como passo seguinte, foi determinado o limite da bacia do rio Apeú com base em dados georreferenciados do relevo da área em questão, derivados de produtos Shuttle Radar Topography Mission (SRTM), a partir da ferramenta Hidrology, que, por sua vez, funciona acoplada ao programa 
ArcGis 9.3. Nesse sentindo, o limite da bacia foi determinado pelos divisores topográficos que circunscrevem a área de drenagem em direção a um canal ou coletor principal.

\section{Pré-processamento de imagem}

Para embasar as análises posteriores, foi realizado o registro das imagens 2004 e 2008, através da imagem de 2001. Em seguida, procedeu-se à conversão dos números digitais (DN) para reflectância aparente, através da metodologia proposta por Markham e Barker (1986).

\section{Elaboração do mapa de cobertura vegetal e de uso da terra}

A imagem, já retificada, foi submetida ao processo de classificação a partir do algoritmo de máxima verossimilhança, que, por ser ligado ao método supervisionado, necessita de um conhecimento prévio das feições ocorrentes na área de estudo. Tal análise teve apoio do trabalho de campo, permitindo, assim, correlacionar as feições espectrais presentes nas imagens com padrões de cobertura vegetal e de uso da terra observados no campo.

Após a coleta de amostras das classes de interesse, foi efetuada uma análise do desempenho das mesmas, sendo, a seguir, gerada a classificação, visando obter o maior índice Kappa. A partir do mapeamento para as geoclasses, foram realizadas edições temáticas, de modo a refinar as informações presentes na imagem.

\section{Mapeamento das áreas de preservação permanente (APPs)}

O procedimento que definiu as Áreas de Preservação Permanente foi efetuado ao longo dos cursos d'água e nas nascentes, utilizando-se o programa ArcGis 9.3, em que foram criados buffers de $30 \mathrm{~m}$ para cada margem do rio ao longo de toda a drenagem da bacia, e de $50 \mathrm{~m}$ para as nascentes. Esse limite está fundamentado no Código Florestal Brasileiro (BRASIL, 1965) e na resolução CONAMA $n^{\circ}$ 303/2002 (BRASIL, 2002), que define a área mínima de preservação permanente para os cursos d'água com menos de dez de largura e para as nascentes, independentemente de seu tamanho.

\section{Mapa de conflito de uso nas APPs}

Para a definição das áreas de conflito de uso nas APPs, foi realizada uma sobreposição, ou overlay, do mapa das APPs com o mapa de uso e cobertura da terra obtida da área de interesse. Tal procedimento delimitou as unidades de uso que estão inseridas nos limites considerados para APPs ao longo dos cursos d'água e ao redor das nascentes. Assim, definiram-se as seguintes classes para categoria de uso inadequado: solo exposto - regiões com nível de edificações consideráveis ou sob preparo de alguma atividade produtiva; agricultura/reflorestamento - áreas produtivas oriundas de monoculturas de espécies tanto agronômicas como florestais; pastagem - áreas formadas por grandes extensões de terra, dominadas por espécies forrageiras; e áreas de mineração - áreas que apresentam superfícies de terra exposta, desencadeadas por atividades mineradoras. Já para uso adequado, as classes foram: Floresta Ombrófila Densa - superfícies com formações de florestas pioneiras da Amazônia oriental, constituídas comumente por árvores atingindo os $40 \mathrm{~m}$ de altura; e sucessão secundária - vegetações em diferentes estágios de regeneração.

\section{RESULTADOS E DISCUSSÕES}

A bacia hidrográfica do rio Apeú, no geral, se caracteriza topograficamente como predominantemente plana, facilitando análise no que tange às categorias de APPs. Considerando essa condição e o tempo reduzido para análises, adotaram-se as medições de 30 e 50 metros de áreas de APPs para, respectivamente, as margens dos cursos d'águas e para as nascentes que compõem a bacia hidrográfica do rio Apeú. Pode se dizer, com isso, que a identificação das APPs ocorreu essencialmente em nível de imagem e com base em dados cartográficos.

Segundo a legislação, a área mínima de preservação permanente ao longo dos cursos d'água na bacia do rio Apeú deveria ser de $1.274,95$ ha, ou $12,74 \mathrm{~km}^{2}$, equivalentes a $4,05 \%$ da área total da bacia. As áreas de preservação permanente em torno das nascentes dos rios, por sua vez, deveriam corresponder a 49,34 ha $\left(0,49 \mathrm{~km}^{2}\right)$, equivalentes a $0,15 \%$ da área total da bacia. Assim, chega-se a um valor total mínimo de área de preservação de 1.324,29 ha, o que corresponde a 4,20\% da área total da bacia. 
Observando a participação de cada município na BHRA, a influência maior nas APPs é de Castanhal, a qual possui uma área de APP com 1.128,8158 ha. Já os municípios de Santa Izabel do Pará e de Inhangapi são responsáveis por 122,6281 ha e 72,8567 ha, nessa ordem.

A transformação na cobertura vegetal atribuída por intervenções urbanas, portanto, vem acontecendo de forma mais dinâmica na região superior da bacia, cuja configuração hídrica, por estar envolvida, em extensão, numa maior área de ocupação humana, recebe intensamente condições adversas da ação antrópica. O plano diretor constitui um importante instrumento de política urbana e de planejamento municipal, por meio do qual se determinam as formas de uso do solo e de exercício do direito de propriedade (PADILHA; SALVADOR, 2006). No caso do plano diretor de Castanhal, há indicativos de preservação e proteção das APPs dentro de uma política territorial de zonas ambientais (CASTANHAL, 2006). No caso do município de Santa Izabel do Pará, segundo Ximenes et al. (2001), o plano diretor (SANTA IZABEL DO PARÁ, 2006) tem capítulo específico para a política de utilização sustentável de recursos naturais, tendo como principal objetivo articular mecanismos para preservação do meio ambiente e redução de impactos ambientais.

Em nível federal, fica suprimida qualquer dúvida sobre as APPs, já que, legalmente, deve-se evitar o máximo possível de ocupações que ocasionem alterações nessas áreas, sendo permitidas somente em situações especiais, em que o órgão ambiental competente pode autorizar a intervenção ou supressão de vegetação para a implantação de obras, planos, atividades ou projetos de utilidade pública ou interesse social, de maneira sustentável (Lei 4.771/65).

\section{Mapeamento de conflitos de uso nas APPs}

Com base na área mínima requerida de APPs, fez-se o seu mapeamento e análise de conflito de uso e ocupação do solo. Os buffers gerados incluíam as áreas de uso adequado (áreas ocupadas por Floresta Ombrófila Densa e sucessão secundária) e de uso inadequado (áreas ocupadas por solo exposto, agricultura/reflorestamento, pastagem e áreas de mineração) para os anos de 2001, 2004 e 2008.

Observou se que, nos três anos analisados, a bacia do rio Apeú estava com de $21 \%$ das áreas marginais dos cursos d'água, espaço destinado às APPs, ocupados de forma inadequada. Assim como as nascentes, que tiveram mais de $38 \%$ de suas APPs tomadas por usos irregulares.

Um dos usos inadequados evidenciados nas áreas de preservação permanente da bacia hidrográfica do rio Apeú foi a presença do solo exposto, caracterizado pela retirada completa da cobertura vegetal ao longo dos cursos d'águas, lugar onde deveria existir mata ciliar.

Nos três momentos de análise, a área ocupada pelo solo exposto esteve entre 8 e 14\% (Figura 1). Conforme Silveira et al. (2005), a mata ciliar confere proteção ao solo contra o impacto direto das gotas de chuva, diminuindo a velocidade de escoamento superficial e favorecendo a infiltração de água no solo através de caminhos preferenciais formados por seu sistema radicular.

Nas nascentes, a presença de 14 a $17 \%$ de solos expostos evidenciou processos de degradação ainda mais graves, à medida que a retirada da cobertura vegetal, de acordo com Lima (2008), implica diminuição da vazão das nascentes, em médio e em longo prazo, acarretando consequentemente a eliminação gradativa dos rios alimentados por essa nascente.

Trabalho de autores como Faria (2000), Tucci (2002) e Mendes e Lima (2007) já trataram de assuntos relacionados à influência das coberturas vegetais nos fluxos das águas. Linhares (2005), ao realizar um estudo no rio Ji-Paraná, em Rondônia, constatou que, entre os anos de 1984 e 2001, o desflorestamento que ocorreu de até 55\% nas APPs ocasionou um incremento nas taxas de deflúvio na região. No entanto, adicionalmente, o autor enfatiza que o volume de água e de energia que circula em bacias de larga escala, principalmente na Amazônia, é muito grande e os efeitos hidrológicos das mudanças de uso e de cobertura da terra não são tão visíveis quanto em bacias de pequeno porte.

Por outro lado, as condições de variação de área vegetativa próximo aos rios, por menor que seja, tendem a criar instabilidade nas zonas ripárias, levando em consideração o encadeamento da estrutura hídrica em si. Machado (2003) corrobora essa ideia quando diz que os maiores rios nada mais são que a junção de afluentes formados por rios menores. Além disso, existe a função hidrológica das florestas ciliares, que está ligada a uma série de fatores importantes para a manutenção da microbacia, sendo que seus efeitos não são apenas locais, refletindo na qualidade de vida de toda a população que se encontra sob influência de uma bacia hidrográfica (PADILHA; SALVADOR, 2006). Um exemplo é a implantação 
de práticas agrícolas após o desflorestamento nessas áreas, que podem conduzir consequentemente à contaminação das águas por compostos químicos utilizados no manejo.

Não menos preocupante que o solo exposto, a classe pastagem foi também evidenciada no local, ocupando de 10 a $13 \%$ das áreas de APPs nas margens dos cursos d'água. Nas nascentes, a ocupação esteve entre 22 e $29 \%$ da área destinada à preservação (Figura 1). Segundo Felippe e Magalhães Júnior (2003), as nascentes são elementos hidrológicos de importância primária para a dinâmica fluvial, pois marcam a passagem da água subterrânea para a superfície pela exfiltração.

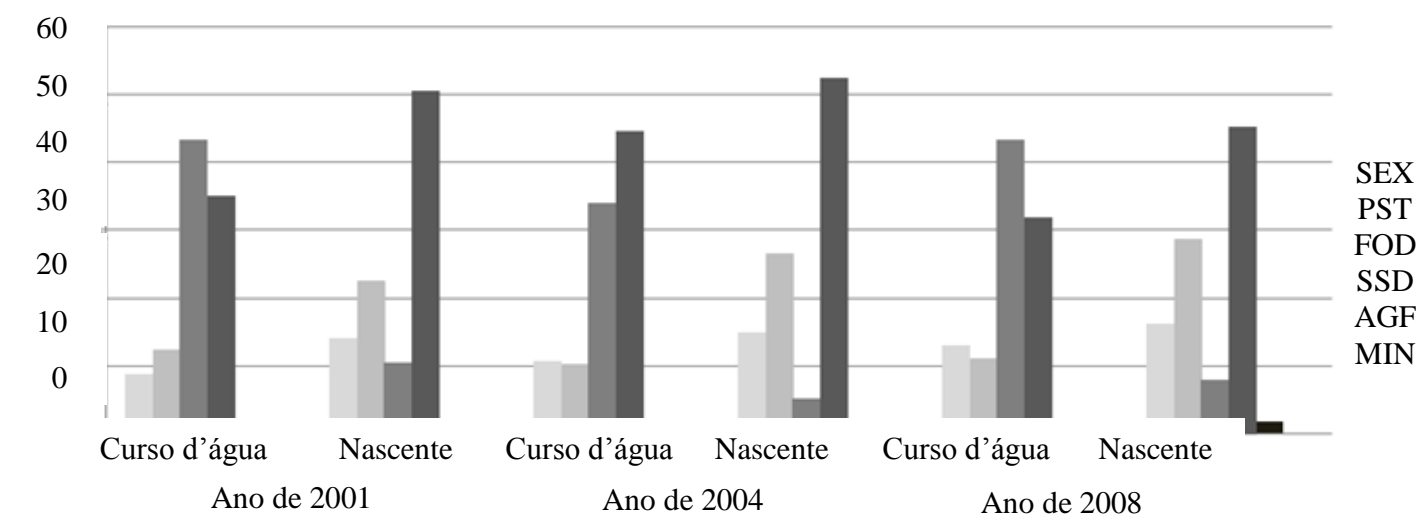

Classes de cobertura vegetal e uso do solo: Solo exposto (SEX), pastagem (PST), floresta ómbrofila densa (FOD), sucessão secundária (SSD), agricultura/reflorestamento (AGF), áreas de mineração (MIN).

Figura 1. Área ocupada pelas classes de cobertura vegetal e uso do solo nas áreas de preservação permanente da bacia hidrográfica do rio Apeú.

Figure 1. Occupied area by land cover classes and soil use in the permanent preservation areas of Apeú river basin.

De acordo com o Instituto Socioambiental (2006), certamente a taxa de desmatamento na região da Amazônia Legal apresenta uma relação direta com a expansão das atividades agropecuárias nessa região. No que concerne ao desmatamento para a formação de pastagens para o gado, Fearnside (2005) comenta que a atividade é considerada uma "melhoria" para a obtenção e a manutenção do título da terra.

A expansão contínua da atividade da pecuária, particularmente a de corte, em relação à agricultura na região tem basicamente a lucratividade como grande indutor. Dados do IBGE na pesquisa da pecuária municipal evidenciam o entusiasmo na produção entre os anos de 1990 e 2006, em que o rebanho bovino cresceu a uma taxa de 6,74\% ao ano na região da Amazônia Legal, enquanto que no resto do Brasil o crescimento médio do rebanho foi de $0,57 \%$ ao ano. Com essas taxas, o rebanho cresceu de 26 milhões de cabeças em 1990 para 73,7 milhões em 2006, mais de 180\% em 16 anos. Só no estado do Pará o incremento de aproximadamente 5 milhões de cabeças, entre os anos de 2000 e 2008, representou no país uma contribuição de 18,40\% no efetivo bovino (IBGE, 2009).

Além da lucratividade, outros elementos vêm contribuindo para o estabelecimento do setor na região amazônica, como status sanitário dos rebanhos da Amazônia, expansão sólida de uma rede de frigoríficos na região, problemas sanitários em rebanhos bovinos de outros países, aumento de demanda por carne bovina em países emergentes etc. (INSTITUTO SOCIOAMBIENTAL, 2006).

Dentro do cenário da BHRA, a influência maior da classe pastagem está diretamente ligada ao município de Castanhal. Tanto por ser o município com maior intervenção na bacia, como também por conter o maior contingente de rebanho bovino em relação aos outros municípios (Santa Izabel do Pará e Inhangapi), com uma média de crescimento anual, entre os anos de 2000 a 2008, de 563 no número de cabeças, ou 5,48\%, incluindo-se nesse valor o ano de 2006-2007, que apresentou uma queda no número de cabeças. Já em relação a Santa Izabel do Pará e Inhangapi, somente Inhangapi se sobressaiu em termos 
de crescimento, com uma contribuição de 5,38\% ao ano, considerando aqui também o intervalo dos anos de 2003-2004 e 2006-2007, quando foram constatadas diminuições no efetivo bovino.

A presença de pastagem em APPs dentro da bacia também foi evidenciada no estudo desenvolvido por Santos (2006), que menciona o risco de compactação do solo por meio do pisoteamento do gado, dificultando assim a regeneração natural. Essa compactação diminui sensivelmente o poder de infiltração da água em regiões mais profundas, desencadeando processos erosivos e inundações mais intensas. Além disso, como foi visto por Soares (2008) em um estudo realizado na região da Bacia Hidrográfica do Rio Madeira (MA), a pecuária também pode desenvolver outras formas de degradação ambiental, como o assoreamento dos corpos de água e a perda de diversidade da flora e da fauna na região de expansão da atividade.

As Áreas de Preservação Permanente, apesar do aumento e maior atenção conferida a partir do ano de 1965, ainda é alvo de ocupação da terra em áreas próximas aos corpos d'água na rede de drenagem em questão, uma vez que cerca de $22 \%$ das áreas de preservação permanente da bacia necessitam de atividades de recuperação ambiental, como o controle da erosão, enquanto que $78 \%$ correspondem de fato às APPs previstas por lei. Nessa condição, a vegetação que recobriria a rede de drenagem contribuiria para a regularização do fluxo hídrico, tanto na manutenção dos aspectos de porosidade da superfície do solo como na viabilização da evapotranspiração das plantas (VALENTE; GOMES, 2005), favorecendo também o aumento da umidade atmosférica e, consequentemente, a manutenção das chuvas.

Ainda considerando-se o contexto histórico da região, pode-se dizer que as atividades agropecuárias construídas ao longo do tempo não deixaram escapar as Áreas de Preservação Permanente, as quais devem ter uma maior atenção na gestão territorial e ambiental da Bacia Hidrográfica do Rio Apeú, de modo a garantir o seu desenvolvimento, sem afetar a preservação dos seus recursos naturais.

\section{CONCLUSÃO}

- Dentro da proposta do estudo de identificação e mapeamento do conflito de usos nas Áreas de Preservação Permanente, foi possível obter informações de suma importância para decisões futuras na gestão territorial da Bacia Hidrográfica do Rio Apeú, onde o uso indevido de $22 \%$ das matas ciliares é consideravelmente baixo.

- As relações de uso e ocupação estabelecida na região do entorno da bacia ainda mostraram que as Áreas de Preservação Permanente apresentam uma relativa manutenção no ambiente, indicando que a legislação que limita a largura da mata ciliar está sendo eventualmente respeitada e, consequentemente, a função hidrológica das florestas ciliares estão sendo preservadas.

- As unidades de uso pastagem e solo exposto foram as que mais ocuparam espaço nas áreas das APPs e, consequentemente, as que mais contribuíram para o processo de desflorestamento da vegetação nas áreas estudadas. Nesse sentindo, sobre os verdadeiros agentes transformadores do espaço da BHRA, pode-se dizer que são essencialmente personagens que foram construídos ao longo da história de ocupação da região nordeste do Pará, caracterizada originalmente por uma política socioeconômica que deixou como vestígios graves impactos ambientais, entre os quais o desmatamento, a perda da biodiversidade e o assoreamento dos corpos d'água.

- Por fim, o uso de técnicas de sensoriamento remoto e geoprocessamento, através do emprego de produtos orbitais do Landsat e classificação de imagem, mostrou-se relativamente eficiente para a definição do uso do solo em Áreas de Preservação Permanente, na medida em que apresentam algumas restrições para larguras de rios menores de 10 metros. Com isso, a integração da geotecnologia no planejamento de uso do solo é uma alternativa que deve ser considerada no monitoramento ambiental, principalmente nas áreas de APPs.

\section{REFERÊNCIAS}

AMBRÓSIO, L. A.; FASIABEN, M. C. R.; MORAES, J. F. L. Dinâmica dos usos e coberturas da terra em área de preservação permanente na bacia hidrográfica dos rios Mogi-Guaçu e Pardo, no período entre 1988 e 2002. In: Congresso da Sociedade Brasileira de Economia, Administração e Sociologia Rural, 46., 2008., Rio Branco. Anais... Rio Branco: SOBER, 2008. p. 1 - 14. 
ARAÚJO, P. P. (org.). Castanhal: estudo de pesquisa e comprovação hidrológica escala 1:8.000. Belém: CPRM, 1997 [s. p.] il. Programa de Apoio à Gestão Territorial - GATE.

BALBINOT, R.; OLIVEIRA, N. K.; VANZETTO, S. C.; PEDROSO, K.; VALÉRIO, A. F. O papel da floresta em ciclos hidrológicos em bacias hidrográficas. Ambiência, Guarapuava, v. 4, n. 1, 2008. p. 131 - 149.

BORGES, L. A. C.; REZENDE, L. L. P.; COELHO JÚNIOR, L. M. Aspectos técnicos e legais que fundamentam o estabelecimento das APP nas zonas costeiras - restingas, dunas e manguezais. Revista da Gestão Costeira Integrada, v. 9, n. 1, 2009. p. 39 - 56.

BRASIL. Conselho Nacional de Meio Ambiente. Resolução $\mathbf{n}^{0}$ 303, de 20 de março de 2002. Dispõe sobre parâmetros, definições e limites de Áreas de Preservação Permanente. Disponível em: <www.mma.gov.br/port/conama/res/res02/res30302.html >. Acesso em: 23/12/2009.

BRASIL. Lei $\mathrm{n}^{\circ}$ 4.771, de 15 de setembro de 1965. Código Florestal Brasileiro. In: Senado Federal. Legislação Republicana Brasileira. Disponível em: <http://www.planalto.gov.br/ccivil_03/LEIS/L4771. htm>. Acesso em: 18/09/2008.

BRASIL. Ministério das Minas e Energia (MME). Departamento Nacional de Produção Mineral. Projeto RADAMBRASIL. Folha AS 22 e AS 23 - Belém-PA/São Luís-MA: geologia, solos, vegetação e uso potencial da terra. Rio de Janeiro, 1974. 226 p.

CASTANHAL. Plano Diretor de Castanhal 2007-2016. Núcleo Gestor do Plano Diretor Participativo do Município de Castanhal. Castanhal: PM. 2006, 151 p. Disponível em: <http://www.sedurb.pa.gov.br/municipio/castanhal/PD_CASTANHAL.pdf>. Acesso em: 04/2009.

ENVIRONMENT FOR VISUALIZING IMAGES (ENVI). Guia do ENVI. Disponível em: <http://www.envi.com.br/guia_envi>. Acesso em: 11/2009.

ENVIRONMENTAl Systems RESEARCH INSTITUTE (ESRI). Programa ArcGis. Disponível em: <www.esri.com/software/arcgis/index.html>. Acesso em: 02/2009.

FARIA, A. P. Influência da vegetação nos processos fluviais de bacias de $1^{\circ}$ ordem. Revista Brasileira de Recursos Hídricos, v. 5, n. 1, 2000. p. 59 - 68.

FELIPPE, M. F.; MAGALHÃES JÚNIOR, A. P. Consequências da ocupação urbana na dinâmica das nascentes em Belo Horizonte-MG. In: Encontro Nacional Sobre Migrações. 6., 2002, Belo Horizonte. Anais... Belo Horizonte: ABEP. 2002, 19 p. Disponível em: <www.abep.org.br/usuario/Gerencia Navegacao.php?texto_id=3966>. Acesso em: 12/2010.

FEARNSIDE, P. M. Desmatamento na Amazônia Brasileira: histórias, índices e consequências. Megadiversidade, v. 1, n. 1, 2005. p. 113 - 123.

FERREIRA, J. C. V. (org.). O Pará e seus municípios. Belém: SEMEAR/Rede Celpa, 2003. p. 443 - 445.

INSTITUTO BRASILEIRO DE GEOGRAFIA E ESTAtíSTICA (IBGE). SIDRA. Pesquisa Pecuária Municipal. Disponível em: <http://www.ibge.gov.br>. Acesso em: 05/01/2009.

INSTITUTO SOCIOAMBIENTAL. Instrumentos econômicos e financeiros para a conservação ambiental no Brasil: uma análise do estado da arte no Brasil e no Mato Grosso - desafios e perspectivas. 2007. 138 p. Disponível em: <www.socioambiental.org/banco_imagens/pdfs/InstEconomicos.pdf>. Acesso em: $11 / 2010$.

JESUS, A. A. S. Geoprocessamento aplicado à estimativa de perda de solos por erosão laminar na Bacia Hidrográfica do Rio Apeú (nordeste do Pará) - Amazônia Oriental. 2009.102 f. Dissertação (Mestrado em Ciências Agronômicas) - Universidade Federal Rural da Amazônia, Belém.

LENTINI, M.; PEREIRA, D.; CELENTANO, D.; PEREIRA, R. Fatos florestais da Amazônia 2005. Belém: Instituto do Homem e Meio Ambiente da Amazônia, 2005. 142 p.

LIMA, W. P.; ZAKIA, M. J. B. Hidrologia de matas ciliares. In: RODRIGUES, R. R.; LEITÃO FILHO, H.F. Matas ciliares: conservação e recuperação. 2. ed. São Paulo: EDUSP/Fapesp, 2004. cap. 3, p. 33 - 44. 
LIMA, W. P. Hidrologia florestal aplicada ao manejo de bacias hidrográficas. Escola Superior de Agricultura Luiz de Queiroz. Departamento de Ciências Florestais. Piracicaba. 2008. 245 p. Disponível em: 〈http://www.ipef.br/hidrologia/hidrologia.pdf>. Acesso em: 10/05/2009.

LINHARES, C. A. Influência do desmatamento na dinâmica da resposta hidrológica na bacia do rio Ji-Paraná/RO. 2005. 217 f. Tese (Doutorado em Sensoriamento Remoto) - Instituto Nacional de Pesquisa Espacial, São José dos Campos, São Paulo.

LORENA, R. B. Evolução do uso da terra em porção da Amazônia Ocidental (Acre), com uso de técnicas de deteç̧ão de mudanças. 2001. 116 f. Dissertação (Mestrado em Sensoriamento Remoto) Instituto Nacional de Pesquisa Espacial, São José dos Campos, São Paulo.

MARKHAM, B. L.; BARKER. J. L. Landsat MSS and TM post-calibration dynamic ranges, exoatmospheric reflectances and at-satellite temperatures. Landsat User Notes, Lanham, MD: EOSAT, v. 1, n. 8, 1986. 21 p.

MARTINS, S. V. Recuperação de matas ciliares. Viçosa. Minas Gerais: Editorial Emerson de Assis. Aprenda Fácil, 2001. 146 p.

MENDES, C. A. B.; LIMA, W. P. Análise de impactos ambientais de florestas plantadas no contexto de bacias hidrográficas: princípios norteadores. In: Seminário de Recursos Hídricos da Bacia Hidrográfica do Paraíba do Sul: o Eucalipto e o Ciclo Hidrológico, I., 2007,Taubaté. Anais... Taubaté: IPABHI. 2007, p. $263-270$.

PADILHA, D. C. C.; SALVADOR, N. N. B. Estudo do ecossistema das Áreas de Preservação Permanente (APPs) de corpos d'água em zonas urbanas como subsídio a alterações do Código Florestal. In: CONGRESSO BRASILEIRO DE DIREITO URBANÍSTICO, 4., 2006, São Paulo. Anais... São Paulo: IBDU, 2006. v. 1, p. 1 - 20.

RIBEIRO, C. F. A.; ALMEIDA, O. T.; RIBEIRO, S. C. A.; TONELLO, K.; LIMA, K. [2005]. Expansão da pecuária de bovinos e desafios de sustentabilidade da atividade na Amazônia Legal. In: WORKSHOP BRASIL-JAPÃO EM ENERGIA, MEIO AMBIENTE E DESENVOLVIMENTO SUSTENTÁVEL, 3., 2005, Campinas. Anais eletrônicos... Campinas: Universidade de Campinas. 2005. Disponível em: <http://www.cori.rei.unicamp.br/BrasilJapao3/progjb3.php>. Acesso em: 23/09/2010.

RODRIGUES, F.; CARVALHO, O. Bacias hidrográficas como unidade de planejamento e gestão geoambiental: uma proposta metodológica. Revista Fluminense de Geografia 2.[online] Niterói n. 1, jul-dez, 2005. Disponível em: <http://www.agbniteroi.org.br/Revista2/rfg2_texto4.htm>. ISSN 19809018. Associação dos Geógrafos Brasileiros. Acesso em: 07/2010.

SANTA IZABEL DO PARÁ (Estado), Prefeitura Municipal; Câmara Municipal. Lei Municipal $\mathbf{n}^{\mathbf{0}}$ 71/2006, de 05 de outubro de 2006, do Plano Diretor Participativo do Município de Santa Izabel do Pará. Dispõe sobre o Plano Diretor Participativo do Município de Santa Izabel do Pará. 66 f. Santa Izabel do Pará, 05 out. 2006. 1 CD-ROM.

SANTOS, O. C. O. Análise do uso do solo e dos recursos hídricos na microbacia do igarapé Apeú, nordeste do estado do Pará. 2006. 256 f. Tese (Doutorado em Geografia) - Universidade Federal do Rio de Janeiro, Rio de Janeiro.

SANTOS, T. C. C.; CÂMARA, J. B. D. (org.). Geo Brasil 2002: perspectivas do meio ambiente no Brasil. Brasília: Edições IBAMA. 2002. 475 p.

SILVA, M. F. Estudo fitossociológico das Orchidaceae da floresta marginal do rio Apeú, município de Castanhal. 1995. 108 f. Dissertação (Mestrado em Ciências Biológicas) - Universidade Federal do Pará, Belém.

SILVEIRA, E. M. O.; CARVAlhO, L. M. T.; SILVA, A. M. Uso conflitivo do solo nas Áreas de Preservação Permanente no município de Bocaina de Minas/MG. In: Simpósio Brasileiro de Sensoriamento Remoto, 12., 2005, Goiânia. Anais... São José dos Campos: INPE. 2005, p. 1673 - 1680. 
SOARES, F. V. P. O uso racional das matas ciliares como forma de conservação dos recursos hídricos e desenvolvimento econômico e social das comunidades tradicionais: município de Autazes-AM. In: Simpósio de Pós-Graduação em Geografia do Estado de São Paulo, 8., 2008, Rio Claro. Anais... São Paulo: SIMPGEO. 2008, p. 161 - 178.

TUCCI, C. E. M. Impactos da variabilidade climática e uso do solo sobre os recursos hídricos. Fórum Brasileiro de Mudanças Climáticas. Câmara Temática sobre Recursos Hídricos. 2002. p. 1 - 64. Disponível em: <www.iph.ufrgs.br/corpodocente/tucci/publicacoes/relclima.PDF>. Acesso em: 17/08/2009.

VALENTE, O. F.; GOMES, M. A. Conservação de nascentes: hidrologia e manejo de bacias hidrológicas de cabeceiras. Viçosa: Aprenda Fácil, 2005. 210 p.

VELOSO, H. P.; GOES FILHO, L. Fitogeografia brasileira: classificação fisionômico-ecológica da vegetação neotropical. Salvador: IBGE, 1982. 85 p. Boletim Técnico Projeto RADAMBRASIL.

XIMENES, P. J.; BRANDÃO, A. J. D. N.; LIMA, J. J. F.; RODRIGUES, R. M. Avaliação institucional da política ambiental, de saneamento e de gestão de águas na Região Metropolitana de Belém. In: Simpósio Nacional de Geografia Urbana, 12., 2011, Belo Horizonte. Anais... Belo Horizonte: SIMPURB, 2011. v. 1, p. 1 - 20. 